\title{
The Influence of BHA, BHT and TBHQ on the Oxidation Stability of Soybean Oil Ethyl Esters (Biodiesel)
}

\author{
Anderson K. Domingos, ${ }^{a}$ Emir B. Saad, ${ }^{a}$ Wellington W. D. Vechiatto, ${ }^{b}$ Helena M. Wilhelm ${ }^{c}$ \\ and Luiz P. Ramos ${ }^{*, a}$ \\ ${ }^{a}$ Centro de Pesquisa em Química Aplicada, Departamento de Química, Universidade Federal do Paraná, \\ CP 19081, 81531-990 Curitiba - PR, Brazil \\ ${ }^{b}$ Centro Brasileiro de Referência em Biocombustíveis, Instituto de Tecnologia do Paraná, \\ Rua Prof. Algacy Munhoz. Maeder, 3775, 81350-010 Curitiba - PR, Brazil \\ ${ }^{c}$ Departamento de Química Aplicada, Instituto de Tecnologia para o Desenvolvimento, \\ 81531-990 Curitiba - PR, Brazil
}

\begin{abstract}
O efeito de antioxidantes sintéticos, como BHT (butil-hidroxitolueno), BHA (butilhidroxianisol) e TBHQ ( $t$-butil-hidroxiquinona), foi avaliado sobre o período de indução de uma amostra de ésteres etílicos de óleo de soja de baixa estabilidade à oxidação, empregando o método Rancimat (EN14112). Efeitos de interação também foram investigados empregando-se um planejamento fatorial, que teve como níveis mínimos e máximos as concentrações de zero e 1500 ppm de cada antioxidante. Dentre os antioxidantes sintéticos avaliados, o BHT apresentou maior eficácia nas concentrações compreendidas entre 200 e 7000 ppm. O TBHQ apresentou maior potencial estabilizador quando utilizado em concentrações mais elevadas, enquanto que o BHA mostrou-se pouco efetivo nesta amostra, sendo que em concentrações superiores a 2000 ppm, não proporcionou qualquer acréscimo do período de indução. $\mathrm{O}$ uso combinado destes antioxidantes, nos níveis testados neste estudo, não evidenciou qualquer efeito sinérgico positivo que justifique o seu uso em misturas binárias ou ternárias.
\end{abstract}

The effect of synthetic antioxidants such as BHT (butyl-hydroxytoluene), BHA (butylhydroxyanisol) and TBHQ ( $t$-butyl-hydroxyquinone) was evaluated on the induction time of soybean oil ethyl esters with low oxidation stability, employing the Rancimat method (EN14112). Interaction effects were also investigated by employing a $2^{3}$ factorial design, which had as minimum and maximum levels the concentrations of zero and $1500 \mathrm{ppm}$ of each antioxidant. Among the synthetic antioxidants evaluated, BHT displayed the highest effectiveness in the concentration range from 200 to $7000 \mathrm{ppm}$. TBHQ displayed a greater stabilizing potential when used at higher concentrations (8000 ppm), while BHA was found to provide no noticeable increase in the induction time at concentrations greater than $2000 \mathrm{ppm}$. The combined use of these antioxidants, at the levels tested in this study, yielded no evidence of any positive synergic effect that would justify their use in binary or ternary mixtures.

Keywords: biodiesel, ethyl esters, antioxidants, oxidation stability, Rancimat method

\section{Introduction}

The policy for inserting biodiesel in the Brazilian energy matrix was recently enacted by the Brazilian Government through Law 11097 from January 13, 2005, which established that the use of B2 mixtures (petrodiesel containing $2 \%$ biodiesel by volume) shall become mandatory starting in 2008. ${ }^{1-4}$ This year, the use of the B5

*e-mail: 1ramos@quimica.ufpr.br mixture (or the addition of 5\% of biodiesel in petroleum diesel) will be authorized, becoming mandatory only as of 2013. In principle, this plan shall be re-evaluated periodically, and if there are qualitative and quantitative increases in national production, a new timeline may be established with the medium-range perspective of increasing the level up to $20 \%$ (B20).

By definition, biodiesel is a natural substitute for petroleum diesel that may be produced from renewable resources such as vegetable oils, animal fats and used 
cooking oil (oils used for deep-frying). ${ }^{3-8}$ Chemically, this product was defined in Resolution No. 42 of the National Agency for Petroleum, Natural Gas and Biofuels (ANP-Agência Nacional de Petróleo, Gás Natural e Biocombustíveis) as alkyl-esters from fatty acids derived from naturally occurring lipids, which may be produced, along with glycerin, through the reaction of triacylglycerides with ethanol or methanol, in the presence of an acid or base catalyst. ${ }^{9}$

The raw materials commonly used for obtaining biodiesel are composed, mostly, by long-chain fatty acids connected by ester-glyceride bonds. For example, soybean oil contains triacylglycerides for which the composition includes linoleic $(53 \%)$, oleic $(23 \%)$, palmitic $(11 \%)$, linolenic $(8 \%)$ and stearic $(4 \%)$ acids. ${ }^{10}$ Therefore, the presence of high levels of unsaturated fatty acids, drawing attention particularly to the presence of about $8 \%$ of linolenic acid, makes this oil very susceptible to oxidation, and this characteristic is inevitably passed on to the methyl or ethyl esters (biodiesel) obtained from this raw material.

Given the magnitude of the soybean agribusiness in the Brazilian market, it is relatively easy to recognize that this oil-bearing crop presents the greatest potential for serving as a model for the immediate development of a national biodiesel program. Just as an example, data made public by ABIOVE (Associação Brasileira da Industria de Óleos Vegetais-Brazilian Association of Vegetable Oil Industries, www.abiove.com.br) demonstrated that the industrial sector is already prepared to meet the national demand for B5 mixtures. ${ }^{11}$ Therefore, the oxidation stability of biodiesel derived from soybean oil must be a concern for both producers and future consumers of this product. This is because oxidative processes promote increased viscosity through the occurrence of condensation reactions involving double bonds. These reactions, in more advanced stages, can lead to the formation of insoluble materials, such as gums and sediments that plug fuel filters and injection systems. ${ }^{12}$ Furthermore, the increase in acidity and the presence of hydroperoxides, both arising from the onset of oxidative processes, can cause the corrosion of fuel system components, as well as attacking the elastomers. ${ }^{12,13}$

In this context, the use of effective antioxidants that increase the stability of soybean oil biodiesel, is of fundamental importance to maintaining a program aimed at its production and use.

Given that factors such as the presence of air, heat, light and pro-oxidants such as hydroperoxides and metals are known to be responsible for the onset of oxidation reactions, some papers have offered suggestions for increasing the stability of these fatty acid esters, typically through the inhibition or elimination of adverse factors. Bondioli et al. (quoted by Dunn ${ }^{14}$ ), observed that storage of ethyl and methyl esters from sunflower oil in an inert atmosphere is extremely efficient for the preservation of the quality of the product. Knothe and Dunn ${ }^{15}$ evaluated the pro-oxidant effect of copper, iron and nickel, and concluded that copper shows the greatest catalytic effect. Therefore, these authors recommended that levels of copper contamination should be carefully controlled, both in biodiesel and in the raw materials necessary for its production.

Although there are many bibliographical references about the effect of natural and synthetic antioxidants on the stability of vegetable oils and fats used for food-related purposes, few studies have been aimed at the use of these materials for automotive or energy-related purposes (biodiesel). This scarcity is even more critical for ethylbase biofuels (ethyl esters).

It is known that natural antioxidants, which are often present in the raw materials used for producing biodiesel, are only partially transferred to the corresponding esters in concentrations that depend fundamentally on the production technology used. ${ }^{16}$ Therefore, depending on the degree of removal of these compounds and especially the degree of unsaturation of the esters produced, the addition of synthetic antioxidants and/or the reintroduction of the natural antioxidants originally present in the starting material can be rather crucial for practical applications. ${ }^{17}$

Mittelbatch and Schober ${ }^{18}$ found that the efficiency of a given antioxidant depends on the raw material and the technology employed in producing the biodiesel, which underscores the importance of carrying out specific investigations for esters produced by different reaction pathways. In the same paper, the antioxidant effect of pyrogallol (PY), propylgallate (PG), tert-butyl hydroxyquinone (TBHQ), butylated hydroxyanisol (BHA) and butylated hydroxytoluene (BHT) on methyl esters was studied. Esters from sunflower and canola oil, oils from deep-frying and animal tallow were tested, distilled and not distilled, in antioxidant concentrations ranging from 100 to 1000 ppm. By using the Rancimat method, it was determined that PY, PG, BHA and TBHQ significantly increased the stability of samples being studied, while BHT was not very efficient.

Dunn $^{14}$ evaluated the antioxidant effect of BHT, TBHQ, BHA, propyl gallate (PrG) and $\alpha$-tocopherol, using pressurized differential calorimetry, and recommended the use of BHA and TBHQ in concentrations greater than 3000 ppm to adjust the oxidation stability of methyl esters from soy oil.

Motivated by the evident shortage of technical data on the factors that influence the stability of different 
samples of biodiesel, the European Committee for Standardization, between the years of 2001 and 2003, developed the project titled "Stability of Biodiesel" (BIOSTAB). ${ }^{19}$ Samples of methyl esters from canola and sunflower oil, used frying oil and tallow were studied with the objective of determining which methods should be used to determine this stability parameter, what effect different storage conditions might have on this property and how to correct it through the addition of antioxidants.

With respect to the methods available for determining oxidation stability, the standard method EN 14112, commonly referred to as the Rancimat method, was adopted as the standard method for determining biodiesel oxidation stability in Europe ${ }^{17}$ and, more recently, in Brazil, through Resolution No. 42 of the ANP. ${ }^{9}$ This method has been considered the most appropriate because the induction time (IT), which is derived from a conductivity measurement in the final product, displayed the best correlation with the stages involved in the onset or preliminary events of oxidative degradation, when compared to other methods from the American Oil Chemistry Society (AOCS). Examples of these include the peroxide index (method $\mathrm{Cd} 8-53$ ), the acid number (method $\mathrm{Cd} 3 \mathrm{~d}-63$ ) and the $o$-anisidine value (method $\mathrm{Cd}$ 18-90), as well as the pressurized differential scanning calorimetry (P-DSC) method. ${ }^{17,19}$

Another method commonly used for evaluating a particular vegetable oil's susceptibility to oxidation is the iodine value, which reveals the degree of unsaturation of a given sample. However, this method is not considered adequate for determining oxidation stability of biodiesel because it does not allow the distinction of effects that are inherent to the different types of fatty acids present in the sample. ${ }^{8,17}$

Storage tests conducted during the BIOSTAB project demonstrated that, just as for the raw materials (vegetable oils and animal fats), temperature, light, air, and the presence of pro-oxidants also have a strong influence on the oxidation stability of biodiesel. ${ }^{17,19}$

Although it is one of the most important sources of information about oxidation stability for biodiesel, the results obtained through the BIOSTAB project are not entirely applicable to the Brazilian reality. This is because it is a study designed to meet European needs, where the biodiesel program production is predominantly based on methyl esters and on the use of rapeseed oil as raw material.

A similar argument has led the U.S. biodiesel industry to undertake a series of field trials to evaluate the appropriateness of the Rancimat method to assess the oxidation stability of biodiesel. ${ }^{17}$ The vast majority of the biodiesel produced in the U.S. is derived from soybean oil. Knowing that soybean oil contains $\mathrm{ca}$. $8 \%$ of linolenic acid and an iodine number of approximately 120 (the low oxidation stability of soybean oil alkyl esters is inherently linked to the chemistry of soybean oil), the minimum IT of 6 hours established in the European EN 14112 standard is hardly achievable by most of the U.S. soybean based biodiesel product. ${ }^{21}$ Nevertheless, many experiments and field tests have shown that soybean oil biodiesel performs well in compression ignition engines, particularly when used in blends. This has motivated a survey for the availability of other methods that could correlate well with engine performance and storage stability, such as the ASTM D2274 for deposit formation under accelerated oxidation with acid number or viscosity measurements in the sample filtrate. In the meantime, the Rancimat method remains generally accepted as a good reference for measuring oxidation stability but the limit of 6 hours has been considerably questioned by many critical players of this fast developing industry. Preliminary data for field trials referred to as The Drum Test ${ }^{21}$ have suggested that this value could be dropped to 2.5 hours without compromising the practical use of the analytical measurement. The U.S. National Biodiesel Board is currently applying for a decrease in this stability requirement in the ASTM 6751 in order to avoid ruling out samples that do not comply with the current limit but do not offer any harm to the well functioning of diesel engines.

In Brazil, the wide diversity and availability of renewable lipid sources for biodiesel production, along with a strong tendency to produce ethyl rather than methyl esters, constitute important arguments for carrying out oxidation stability studies directed at the true objectives of the Brazilian program for the production and use of biodiesel. This paper is addressed to the low oxidation stability of an industrial sample of soybean oil ethyl esters and describes the antioxidation efficiency of three commercially available chemicals, BHT, BHA and TBHQ, along with the concentration levels required to adjust the oxidation stability of this sample to the European EN 14112 standard.

\section{Experimental}

The soybean oil ethyl esters used in this project were obtained from Ecomat Ecológica Matogrossense Ltda. (Cuiabá-MT, Brazil). According to information supplied by the manufacturer, this sample was obtained from refined soybean oil that had been transesterified in alkali medium. The BHA (2(3)-tert-butyl-4-methoxyphenol or butylated hydroxyanisol), BHT (2,6-di-tert-butyl-4methylphenol or butylated hydroxytoluene), and TBHQ 
(2-tert-butylbenzene-1,4-diol or tert-butyl-hydroxyquinone), all with purity grades above $99 \%$, were provided by NutriCom Technology Ltd. (São Paulo-SP, Brazil).

Samples of ethyl esters were initially subjected to the analyses specified by Resolution No. 42 of the ANP, using the methods reported in Table $1 .{ }^{9}$ From that point, concentrations ranging from 200 to $8000 \mathrm{ppm}$ of each of these antioxidants were added to $100 \mathrm{~g}$ portions of the original sample, by means of vigorous mechanical agitation, and the mixtures were later subjected to the determination of their respective induction times (IT) in a model 743 Rancimat system (Metrohm AG, Herisau, Switzerland), according to official method EN 14112.

The IT determinations were carried out at the Brazilian Reference Center for Biofuels (Centro Brasileiro de Referência em Biocombustiveis-CERBIO, Curitiba-PR, Brazil) at an air flow rate of $10 \mathrm{~L} \mathrm{~h}^{-1}$. The temperature of the heating blocks was adjusted to $110{ }^{\circ} \mathrm{C}$ and the temperature correction factor (DT) was adjusted to $1.5^{\circ} \mathrm{C}$, as recommended by the manufacturer.

The efficacy of all antioxidants was expressed in terms of the stabilization factor, $\mathrm{F}=\mathrm{IT}_{\mathrm{x}} / \mathrm{IT}_{\mathrm{o}}$, where $\mathrm{IT}_{\mathrm{x}}$ is the induction time in the presence of the antioxidant and $\mathrm{IT}_{\mathrm{o}}$ is the induction time in its absence. Calculations were carried out through the program that comes with the equipment (743 Rancimat Software, version 1.0).
All samples containing 8000 ppm of antioxidant were also subjected to the analysis of water and sediment following the official ASTM D 1796 method to evaluate their respective solubility limits under the conditions established for the test.

Possible interaction effects between BHA, BHT and TBHQ were evaluated by employing a $2^{3}$ factorial design, having as minimum and maximum levels the concentrations of zero and $1500 \mathrm{ppm}$ of each of these antioxidants. Mixtures prepared according to this design were also subjected to the determination of their corresponding IT, following the EN 14112 method. The relative standard deviation of the experimental procedure was evaluated by carrying out a triplicate at the center point (zero levels) of the experimental design.

\section{Results and Discussion}

\section{Characterization of ethyl esters from soy oil}

The soybean oil ethyl esters used in this study presented an oxidation stability of only 0.16 hours (Table 1 ). Resolution No. 42 of the ANP establishes that biodiesel consumed in Brazil is to have an IT of at least 6 hours. Therefore, oxidation stability was the main parameter not in compliance with this legislation and the aim of this work was to evaluate the efficiency of synthetic antioxidants in adjusting this technical parameter.

Table 1. Analyses of samples of ethyl ester from soybean oil in accordance with Resolution No. 42 of the ANP

\begin{tabular}{|c|c|c|c|}
\hline Property & Method & Limit & Ethyl Esters \\
\hline Aspect & - & LII & LII \\
\hline Specific gravity at $20^{\circ} \mathrm{C} /\left(\mathrm{kg} \mathrm{m}^{-3}\right)$ & ASTM D1298/4052 & Report & 881 \\
\hline Kinematic viscosity at $40^{\circ} \mathrm{C} /\left(\mathrm{mm}^{2} \mathrm{~s}^{-1}\right)$ & ASTM D445 & Report & 4.87 \\
\hline Water and sediments/(\%) & ASTM D2709 & 0.05 max. & $<0.05$ \\
\hline Flash point $/\left({ }^{\circ} \mathrm{C}\right)$ & ASTM D93 & $100 \mathrm{~min}$ & 150 \\
\hline Ester content $/(\%, \mathrm{~m} / \mathrm{m})$ & EN 14103 & Report & $\mathrm{Nd}^{\mathrm{a}}$ \\
\hline Carbon residue/(\%, m/m) & ASTM D4530/189 & $0.10 \max$. & 0.11 \\
\hline Sulphated ash/(\%, m/m) & ASTM D874 & 0.02 max. & 0.006 \\
\hline $\operatorname{Sulphur} /(\%, \mathrm{~m} / \mathrm{m})$ & ASTM D4294/5453 & Note & $<0.001$ \\
\hline Copper corrosion for $3 \mathrm{~h}$ at $50^{\circ} \mathrm{C}$ & ASTM D130 & No. 1 max. & 1 \\
\hline Cetane number & ASTM D613 & Report & 60 \\
\hline Cold filter plugging point $/\left({ }^{\circ} \mathrm{C}\right)$ & ASTM D6371 & $3 \max$. & -13 \\
\hline Distillation, $90 \%$ recovered $/\left({ }^{\circ} \mathrm{C}\right)$ & ASTM D1160 & 360 max. & 287 \\
\hline Acid number/(mg KOH g $\left.{ }^{-1}\right)$ & ASTM D664 & 0.80 max. & 0.55 \\
\hline Iodine value & EN 14111 & Report & 119 \\
\hline Methanol or ethanol $/(\%, \mathrm{~m} / \mathrm{m})$ & EN 14110 & $0.5 \max$ & 0.01 \\
\hline Free glycerine $/(\%, \mathrm{~m} / \mathrm{m})$ & ASTM 6854 & $0.02 \max$. & 0.05 \\
\hline Total glycerine/(\%, m/m) & ASTM 6854 & $0.38 \max$. & 0.22 \\
\hline Monoglycerides/(\%, m/m) & EN 14105 & Report & 0.43 \\
\hline Diglycerides $/(\%, \mathrm{~m} / \mathrm{m})$ & EN 14105 & Report & 0.38 \\
\hline Triglycerides $/(\%, \mathrm{~m} / \mathrm{m})$ & EN 14105 & Report & 0.10 \\
\hline Phosphorus/(mg kg-1) & ASTM D4951 & Report & 2.5 \\
\hline Sodium + Potassium/(mg kg-1) & EN 14108/14109 & 10 max. & 6 \\
\hline Calcium + Magnesium/(mg kg $\left.{ }^{-1}\right)$ & EN 14538 & Report & $\mathrm{Nd}^{\mathrm{a}}$ \\
\hline Oxidation stability at $110^{\circ} \mathrm{C} /(\mathrm{h})$ & EN14112 & $6 \mathrm{~min}$ & 0.16 \\
\hline
\end{tabular}

a Not determined. 
Influence of BHA, BHT, and TBHQ on the oxidation stability of ethyl esters from soybean oil

Synthetic chemicals such as BHA, BHT, and TBHQ are primary antioxidants that interrupt the free-radical chain of oxidative reactions by contributing hydrogen from the phenolic hydroxyl groups, themselves forming stable free radicals which do not initiate or propagate further oxidation of lipids. Therefore, these scavenging species must be added as early as possible in the manufacturing process or to the finished product because they cannot reverse the oxidation of rancid oils, nor are they effective in suppressing hydrolytic rancidity which involves the enzymatically catalyzed hydrolysis of fats.

Table 2 shows the IT of the 33 samples tested with BHT, BHA, and TBHQ, in concentrations that varied from 200 to $8000 \mathrm{ppm}$. To evaluate the reliability of the method employed, one of the tests, chosen at random, was carried out in triplicate to allow the calculation of the relative standard deviation (RSD) of the analytic procedure. This test consisted of treating the esters with $3000 \mathrm{ppm}$ of BHT and its RSD was of approximately $0.3 \%$ for an average value of $4.120 \pm 0.012 \%$. As mentioned previously, the sample with no antioxidant presented an IT of 0.16 hours and this value was employed in calculating the respective stabilization factors $(\mathrm{F})$.

The greatest stabilization factors $(\mathrm{F})$ were obtained with the use of $8000 \mathrm{ppm}$ of BHT (35.59) of THBQ (52.53) (Table 2). On the other hand, the greatest stabilization factor of BHA was obtained at a concentration of $1500 \mathrm{ppm}$ (8.18). This result, when compared to the maximum values of $\mathrm{F}$ obtained for BHT and TBHQ, demonstrates the smaller efficiency of BHA in the stabilization of ethyl esters from soybean oil. Curiously, above 2000 ppm, BHA displayed no effect on the stability of the esters, yielding IT values that were practically identical to those of the original sample, with no added antioxidants.

By analyzing Figure 1, one notes that, up to the level of $1500 \mathrm{ppm}$, BHT and BHA were the antioxidants that provided the greatest increases in IT, with the most noteworthy of the two being BHT. For the range of concentrations between 2000 and 7000 ppm, BHT continued being the most effective, providing IT values of about 5.64 hours upon addition of $7000 \mathrm{ppm}$ of this antioxidant. Within the same range (2000-7000 ppm), the effect of TBHQ displayed an increasing linear tendency up to the concentration of $6000 \mathrm{ppm}$, when it underwent an abrupt increase. At $7000 \mathrm{ppm}$, the behavior of TBHQ was relatively similar to that of BHT, providing F values near 31.29 (IT of 5.32 hours).

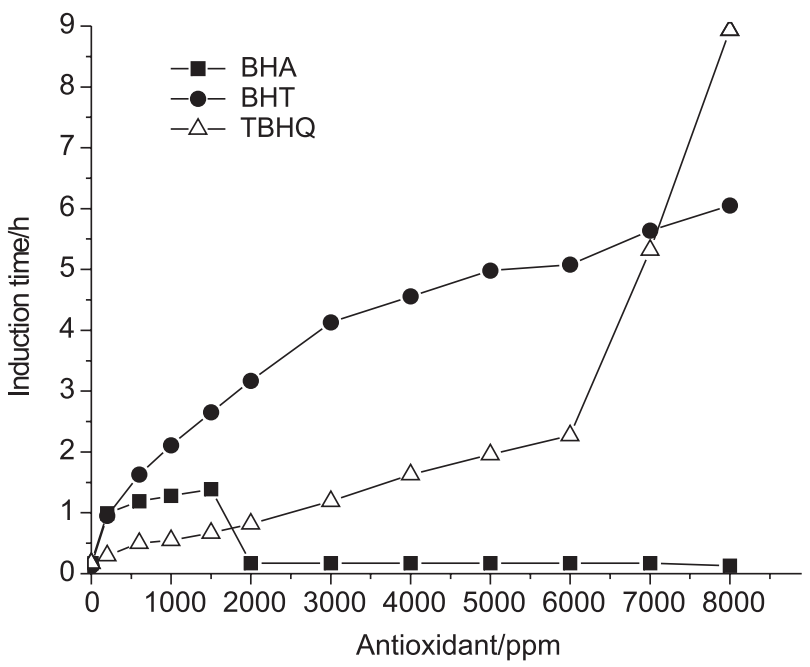

Figure 1. Concentrations of BHA, BHT and TBHQ as a function of induction times.

It was also noted that, at the points corresponding to the maximum concentrations of $8000 \mathrm{ppm}$, TBHQ was the most efficient antioxidant, in contrast with the tendency noted up to concentrations of $7000 \mathrm{ppm}$

Table 2. Effect of adding BHA, BHT, and TBHQ on the oxidation stability of ethyl esters from refined soybean oil

\begin{tabular}{lcccccc}
\hline Antioxidant/(ppm) & \multicolumn{2}{c}{ BHA } & \multicolumn{2}{c}{ BHT } & \multicolumn{2}{c}{ TBHQ } \\
\hline & $\mathrm{IT}^{\mathrm{a} /(\mathrm{h})}$ & $\mathrm{F}^{\mathrm{b}}$ & $\mathrm{IT} /(\mathrm{h})$ & $\mathrm{F}$ & $\mathrm{IT} /(\mathrm{h})$ & $\mathrm{F}$ \\
200 & 0.99 & 5.82 & 0.95 & 5.59 & 0.30 & 1.76 \\
600 & 1.19 & 7.00 & 1.63 & 9.58 & 0.50 & 2.94 \\
1000 & 1.28 & 7.53 & 2,11 & 12.41 & 0.55 & 3.23 \\
1500 & 1.39 & 8.18 & 2.65 & 15.59 & 0.82 & 3.94 \\
2000 & 0.17 & 1.00 & 3.17 & 18.65 & 1.19 & 7.82 \\
3000 & 0.17 & 1.00 & 4.12 & 24.29 & 1.63 & 9.59 \\
4000 & 0.17 & 1.00 & 4.56 & 26.82 & 1.96 & 11.53 \\
5000 & 0.17 & 1.00 & 4.98 & 29.29 & 2.27 & 13.35 \\
6000 & 0.17 & 1.00 & 5.08 & 29.88 & 5.32 & 31.29 \\
7000 & 0.17 & 1.00 & 5.64 & 33.18 & 3.93 & 52.53 \\
8000 & 0.13 & 0.76 & 6.05 & 35.59 & &
\end{tabular}

anduction time; ${ }^{\mathrm{b}}$ Stabilization factor. 
(Figure 1). With 8000 ppm of BHT, the sample's IT reached 6.05 hours. With the addition of BHA at concentrations of $8000 \mathrm{ppm}$, the sample's IT decreased to 0.13 hours, a value $19 \%$ lower than that of the untreated sample. Although numerically smaller than the system's standard deviation, whose calculation was based on triplicate measurements for samples containing $3000 \mathrm{ppm}$ of BHT, a decrease of only 0.03 hours can not be used to characterize a pro-oxidant action of BHA because the corresponding IT measurements were to close to the detection limit of the method. However, studies involving the oxidation stability of fatty acid methyl esters have indicated that BHA has a significant pro-oxidant effect when used at high concentrations. ${ }^{14}$

Mittelbach and Schober ${ }^{18}$ studied the antioxidant effect of BHA, BHT and TBHQ in methyl esters derived from sunflower oil, canola oil, used frying oil and tallow, using a range of concentrations that varied from 100 to 1000 ppm of each of these antioxidants; therefore, a much more restricted range than the one evaluated in the present study. These authors determined that TBHQ was the antioxidant with greatest efficiency on all non-distilled esters from these raw materials, followed by BHA and by BHT. Dunn, ${ }^{14}$ who also evaluated the use of these antioxidants on methyl esters from soybean oil, recommended the use of BHA and TBHQ in concentrations greater than 3000 ppm. In his studies, however, he did not attempt to specify the levels of additives necessary to correct the behavior of esters with low oxidation stability.

Our results demonstrate that the antioxidant action of TBHQ allowed achieving the largest values of F, which was also observed in the papers cited previously. ${ }^{14,18}$ It is important to note, however, that in each case, different ranges of additive concentration were studied in samples of methyl esters produced from different types of raw material. On the other hand, and in contrast with data in the literature, BHT displayed one of the best stabilization performances for soybean oil ethyl esters, along the entire range of concentrations evaluated in this study. Therefore, given its influence on the IT of the other products (Figure 1), this additive can be classified as an important candidate for use in fuels that present oxidation stability not too distant from the limit specified in Resolution No. 42 of the ANP.

None of the samples treated with 8000 ppm of antioxidant failed in the ASTM method D 1796 for water and sediments. Therefore, trends in the experimental data set could not be attributed to problems with solubility or improper sample preparation. On the other hand, there was no attempt to verify whether these high antioxidant concentrations had any negative influence on biodiesel fuel properties. Schober and Mittelbach detected a noticeable increase in acid values at antioxidant levels beyond $1000 \mathrm{ppm}$, while other critical parameters such as kinematic viscosity, specific gravity, carbon residue, cold flow properties and sulfated ash were not affected for different biodiesel samples. ${ }^{22}$ Therefore, if additive levels of 8000 ppm are proven of any practical use, further investigations will be required to demonstrate whether these high concentration levels are not detrimental for some of the most critical properties of the biofuel.

\section{Stabilization effect of BHA, BHT and TBHQ at $90^{\circ} \mathrm{C}$}

Given the absence of an effect from BHA at concentrations greater than 1500 ppm (Figure 1), new tests were carried out to determine whether a decrease in the working temperature for the Rancimat method (110 ${ }^{\circ} \mathrm{C}$, according to the manufacturer) could have a positive influence on the behavior of this antioxidant. A few points from the previous curve were randomly selected and the Rancimat method was carried out at a temperature of $90{ }^{\circ} \mathrm{C}$. These points correspond to the concentrations of 3000 and 5000 ppm which, for the effects of comparison, were also tested with BHT and TBHQ under the same conditions.

In contrast with the absence of effect noted when following the official EN 14112 method $\left(110{ }^{\circ} \mathrm{C}\right.$, Figure 2A), all BHA samples analyzed according to the modified Rancimat method $\left(90{ }^{\circ} \mathrm{C}\right.$, Figure $\left.2 \mathrm{~B}\right)$ displayed improved stabilizing action, with IT values for samples containing 3000 and 4000 ppm of BHA greater than those obtained with BHT at the same concentrations.

Therefore, the temperature of $110{ }^{\circ} \mathrm{C}$, established as standard in the EN 14112 method, seemed to be not adequate for evaluating the oxidation stability of biodiesel samples containing BHA. Therefore, it is possible that this product, under normal temperature and pressure conditions, may display suitable antioxidant activity on biodiesel, particularly those that are not characterized by very low oxidation stability. Carrying out new tests at even lower temperatures could have shed light on this issue. However, this series of experiments has not yet been concluded due to the time required for its completion.

\section{Effects of interaction between BHA, BHT and TBHQ}

Table 3 displays results obtained from the factorial design initially proposed for determining the presence of 

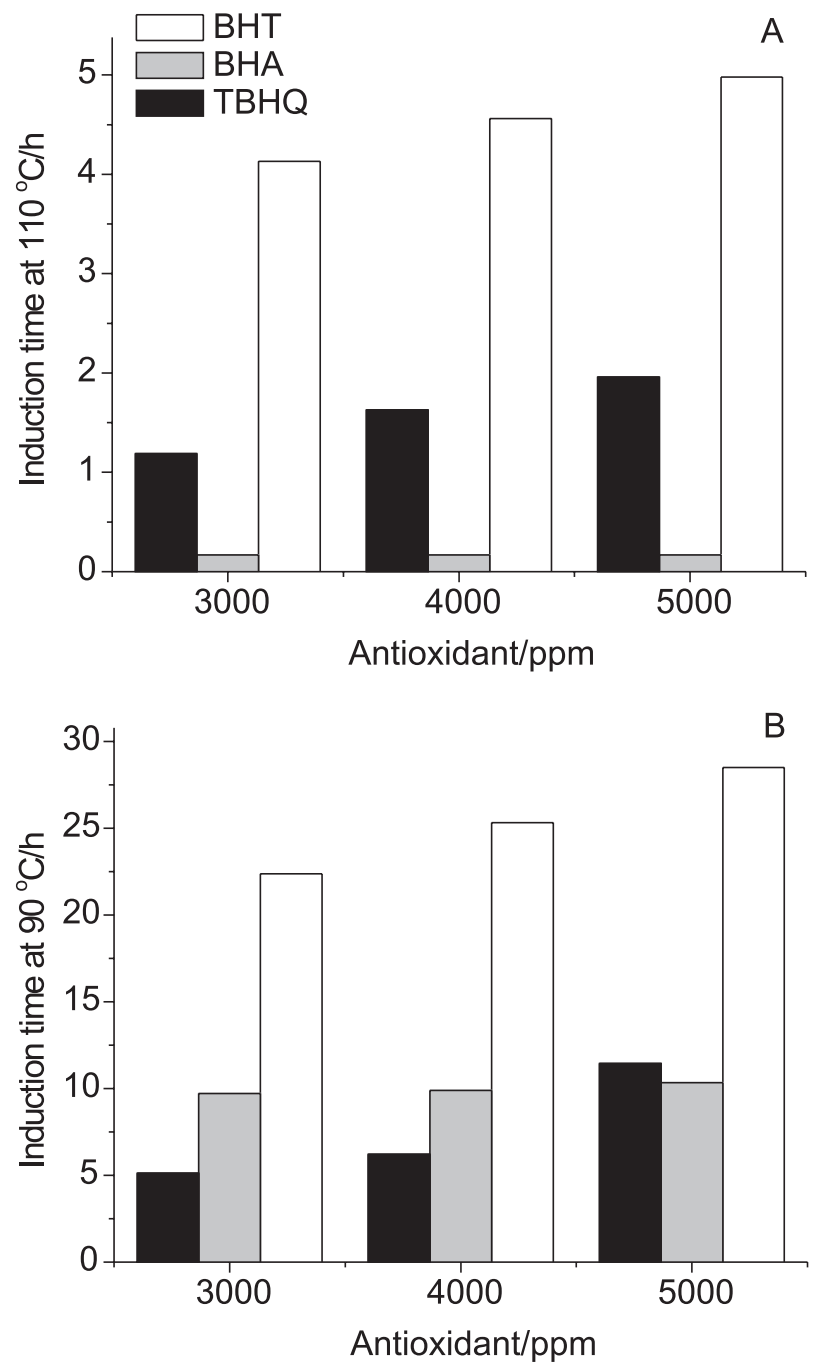

Figure 2. Stabilization effects of BHA, BHT and TBHQ at $110^{\circ} \mathrm{C}$ (A) and at $90{ }^{\circ} \mathrm{C}(\mathrm{B})$.

interaction effects between BHA, BHT and TBHQ. The IT values observed in experiments 4,6 and 7 through 11 correspond to different combinations among the antioxidants tested, while experiments 1, 2, 3 and 5 were carried out as discussed in the previous section, using the antioxidants one at a time.

Based on the standard deviation that was calculated for the triplicate at the central point of the experimental design $(2.02 \pm 0.03)$, the IT for the sample containing only $1500 \mathrm{ppm}$ of BHA (1.39 hours in experiment 2 , Table 3 ) was practically the same as for the sample containing only $1500 \mathrm{ppm}$ of BHA and BHT (1.37 hours in experiment 4, Table 3). Considering that the sample containing only $1500 \mathrm{ppm}$ of BHT displayed an IT of 2.65 hours, one may conclude that the interaction between these two antioxidants was detrimental to the efficiency of BHT, in other words, there was an undesirable prooxidant interaction.
Table 3. Matrix for $2^{3}$ design for evaluation of the occurrence of synergism effects between BHT, BHA and TBHQ

\begin{tabular}{lcccc}
\hline Experiment & $\mathrm{BHA} /(\mathrm{ppm})$ & $\mathrm{BHT} /(\mathrm{ppm})$ & $\mathrm{TBHQ} /(\mathrm{ppm})$ & $\mathrm{IT} /(\mathrm{h})$ \\
\hline 1 & $0(-)$ & $0(-)$ & $0(-)$ & 0.16 \\
2 & $1500(+)$ & $0(-)$ & $0(-)$ & 1.39 \\
3 & $0(-)$ & $1500(+)$ & $0(-)$ & 2.65 \\
4 & $1500(+)$ & $1500(+)$ & $0(-)$ & 1.37 \\
5 & $0(-)$ & $0(-)$ & $1500(+)$ & 0.67 \\
6 & $1500(+)$ & $0(-)$ & $1500(+)$ & 1.65 \\
7 & $0(-)$ & $1500(+)$ & $1500(+)$ & 2.61 \\
8 & $1500(+)$ & $1500(+)$ & $1500(+)$ & 1.93 \\
9 & $750(0)$ & $750(0)$ & $750(0)$ & 2.00 \\
10 & $750(0)$ & $750(0)$ & $750(0)$ & 2.06 \\
11 & $750(0)$ & $750(0)$ & $750(0)$ & 2.00 \\
\hline
\end{tabular}

On the other hand, when BHA was combined with TBHQ (experiment 6, Table 3), there was a slight increase in the stabilizing potential for the sample which, however, did not match the increase expected when the individual effects of these additives are taken into consideration.

The absence of constructive interactions was also observed both by the combination of BHT with TBHQ, and through the simultaneous use of the three antioxidants (experiments 7 and 8). Therefore, the combination of these antioxidants at the levels tested, whether in binary or ternary mixtures, besides not contributing to increasing the stabilization potential for ethyl esters from soybean oil, also caused considerable pro-oxidant effects, when compared to the behavior observed by the action of each of these products acting alone.

\section{Conclusions}

Among the synthetic antioxidants evaluated for the increased stability of soybean oil ethyl esters, BHT displayed the greatest efficacy in concentrations ranging from 200 to $7000 \mathrm{ppm}$, which qualifies it as a good candidate for esters that display oxidation stability not too far from the limit established by Resolution No. 42 of the ANP. ${ }^{9}$ On the other hand, TBHQ displayed a greater stabilizing potential when used in higher concentrations. Therefore, it is ideal for esters with lower stability.

Tests in which the temperature for the Rancimat method was modified to $90^{\circ} \mathrm{C}$ allowed noting that the EN 14112 method may not be adequate for testing samples treated with BHA, since the decrease in the analysis temperature demonstrated that this product can be even more efficient than BHT in stabilizing ethyl esters from soybean oil.

Last, the combined use of these antioxidants, at the levels tested in this study, yielded no evidence of any positive synergic effect that would justify the use of these additives in binary or ternary mixtures. 


\section{Acknowledgments}

The authors acknowledge the logistic and/or financial support from the following funding agencies: Instituto de Tecnologia do Paraná (TECPAR), Instituto de Tecnologia para o Desenvolvimento (LACTEC), CNPq and Fundação Araucária.

\section{References}

1. http://www.biodiesel.gov.br, accessed in January, 2006.

2. Ramos, L.P.; Wilhelm, H.M.; Appl. Biochem. Biotechnol. 2005, 121-124, 807.

3. Ferrari, R. A.; Oliveira, V. S.; Scabio, A.; Quim. Nova 2005, 28,19 .

4. Pinto, A. C.; Guarieiro, L. L. N.; Rezende, M. J. C.; Ribeiro, N. M.; Torres, E. A.; Lopes, W. A.; Pereira, P. A. P.; de Andrade, J. B.; J. Braz. Chem. Soc. 2005, 16, 1313.

5. Schuchardt, U.; Sercheli, R.; Vargas, R. M. ; J. Braz. Chem. Soc. 1998, 9, 199.

6. Zagonel, G. F.; Ramos, L. P.; Rev. Quim. Ind. 2001, 717, 17.

7. Ramos, L. P.; Anais do Congresso Brasileiro de Soja (Proocedings of the Brazilian Soy Meeting), Londrina, Brasil, 1999.

8. Ramos, L. P.; Domingos, A. K.; Kucek, K. T.; Wilhelm, H, M.; Biotecnologia: Ciência e Desenvolvimento 2003, 31, 28. Available electronically at http://www.biotecnologia.com.br/revista/bio31/ biodiesel.pdf

9. ANP, Agência Nacional de Petróleo, Gás Natural e Biocombustíveis, available at http://www.anp.gov.br/petro/ biodiesel.asp, accessed in January, 2006.

10. Gunstone, F. D.; The Chemistry of Oils and Fats, Blackwell Publishing: Boca Raton, 2004.
11. Nappo, M.; Oral Presentation at the $6^{\circ}$ Fórum de Debates sobre Qualidade e Uso de Combustíveis, Instituto Brasileiro de Petróleo (IBP), Rio de Janeiro, Brazil, 2006. Available electronically at http://www.abiove.com.br/palestras_br.html

12. Monyem, A.; Van Gerpen, J.; Biomass and Bioenergy 2001, 20,317 .

13. Tao, Y.; Operation of Cummins N-14 Diesel on Biodiesel: Performance, Emissions and Durability, Final Report to the National Biodiesel Board, Ortech Report No. 95-E11-B004524, 1995.

14. Dunn, R. O.; Fuel Process. Technol. 2005, 72, 1071 and references therein.

15. Knothe, G.; Dunn, R. O.; J. Am. Oil Chem. Soc. 2003, 80, 1021.

16. Ferrari, A. R.; Oliveira, V. S.; Scabio, A.; Sci. Agric. 2005, 62, 291.

17. Prankl, H. In The Biodiesel Handbook; Knothe, G.; Krahl, J.; Van Gerpen, J., eds., AOCS Press: Champaign, 2005, ch. 6.4.2.

18. Mittelbach, M.; Schober, S.; J. Am. Oil Chem. Soc. 2003, 80, 817.

19. Prankl, H.; Biostab Project Summary, http://www.biostab.info, accessed in May, 2005.

20. Lawrence, R.; Oral Presentation at the National Biodiesel Conference and Exposition, San Diego, USA, 2006. Available electronically at http://www.biodieselconference.org/2006.

21. McCormick, R. L.; Alleman, T. L.; Waynick, J. A.; Westbrook, S. R.; Porter, S. Technical Report NREL/TP-540-39721. National Renewable Energy Laboratory, Golden, USA, 2006. Available electronically at http://www.osti.gov/bridge

22. Schober, S.; Mittelbach, M.; Eur. J. Lipid Sci. Technol. 2004, 106, 382 .

Received: June 7, 2006

Web Release Date: April 3, 2007 